\title{
Implications of Community-Based Research for Professional Psychology Training: Reflections from Two Early Career Psychologists
}

\author{
Melissa Tiessen ${ }^{1}$ and Julie Beaulac ${ }^{2}$ \\ ${ }^{1}$ McGill University, ${ }^{2}$ University of Ottawa
}

\begin{abstract}
Author Notes: Melissa Tiessen, Department of Psychology, McGill University; ${ }^{2}$ Julie Beaulac, School of Psychology, University of Ottawa. Melissa Tiessen is now at the Canadian Psychological Association, and Julie Beaulac is now at the Weight Management Clinic, The Ottawa Hospital. Please note that the views expressed in this article are solely those of the authors and do not represent the views of either of the organizations for which they work.

Melissa Tiessen's dissertation research was supported in part by grants from the Canadian Institutes of Health Research, Institute of Aboriginal People's Health (CIHR IAPH), and the Network for Aboriginal Mental Health Research (NAMHR). A very special thanks to the members of the two participating communities (remaining anonymous for privacy reasons), in particular the youth. Thanks as well to Dr.Donald Taylor and Dr. Laurence Kirmayer for their input and support as thesis advisors, and valued comments on early drafts of this article.

Julie Beaulac's dissertation research was supported in part by grants from the Social Sciences and Humanities Research Council of Canada and Sport Canada. A special thanks to community partners from the South-East Ottawa Community Health Centre, Culture Shock Canada, and Heron Road Community Centre (who have given permission for their organization names to be used). In particular, thanks to Madeleine Brenning, Marc-André Clément, Sulaimon Giwa, Cybill Mathelier, and Kelli Tonner. Thanks as well to the young people involved in the hip-hop dance program and their parents. Finally, thanks to Dr. Bob Flynn, Dr. Michelle Fortier, and Dr. Denise Spitzer for their input and support as thesis committee members. Special thanks as well to Dr. Tim Aubry for his comments on a previous version of this article.

Correspondence concerning this article should be addressed to Dr. Melissa Tiessen, Canadian Psychological Association, 141 Laurier Avenue West, Suite 702, Ottawa, Ontario K1P 5J3. E-mail: mtiessen@cpa.ca
\end{abstract}

Keywords: community psychology, community-based research, professional psychology, training, lessons learned

Recommended citation: Tiessen, M., \& Beaulac, J. (2013). Implications of Community-Based Research for Professional Psychology Training: Reflections from Two Early Career Psychologists. Global Journal of Community Psychology Practice, 4(3), 1-11. Retrieved Day/Month/Year, from (http://www.gjcpp.org/). 


\title{
Implications of Community-Based Research for Professional Psychology Training: Reflections from Two Early Career Psychologists
}

\begin{abstract}
Community psychology (CP) has valuable philosophical perspectives and methodological approaches to offer the wider discipline of psychology, yet it remains underappreciated and often invisible in most professional training programs in psychology, including those programs intended to train in the areas of clinical, counselling, school, and neuropsychology. Communitybased research (CBR) is one particular methodological approach within CP that has the potential to enhance standard research training experiences, as well as to enhance professional psychology training more generally. In this paper, we discuss the professional psychology training implications of CBR approaches, highlighting potential changes to the existing training structure that could facilitate wider access to training in CBR, and thereby enhance the competencies of professional psychologists. We also critically reflect on our experiences conducting our own CBR dissertation projects while becoming trained as clinical psychologists. We encourage other trainees, professional psychologists, and training programs to consider the merits of incorporating $\mathrm{CP}$ perspectives and approaches into their work.
\end{abstract}

Keywords: community psychology, community-based research, professional psychology, training, lessons learned

Community psychology $(\mathrm{CP})$ is slowly gaining attention within the Canadian psychology landscape; for example, the journal Canadian Psychology recently published a special issue on CP (Nelson \& Aubry, 2010). The research approach and methods used within $\mathrm{CP}$, such as participatory action or community-based research (CBR), qualitative research, and program evaluation are conducive to responding to the specific needs of a community (Nelson \& Lavoie, 2010). CBR, a research paradigm commonly associated with $\mathrm{CP}$, grew out of an increased recognition of the importance of social and macro-level factors as related to the well-being of individuals and communities, as well, as a response to the critiques of public health research methods, such as the separation of individuals from the larger context that influences their health and behaviors (critiques that could similarly apply to traditional psychological research; Israel, Schulz, Parker, \& Becker, 1998). Various approaches to CBR exist, such as community based participatory research, participatory action research, and action research. All share important commonalities (e.g., principles of collaboration, sharing power) and yet vary along a continuum (Wallerstein \& Duran, 2003). For the purpose of this paper, CBR will refer to research that is "conducted by, for or with the participation of community members...Community-based research aims not merely to advance understanding, but also to ensure that knowledge contributes to making a concrete and constructive difference in the world" (LOKA, 2002, as cited in Flicker \& Savan, 2006, page 3 ).

CBR in Canada has been informed by communitybased participatory research in the United States, such as by the work of Barbara Israel (Roche, 2008). Internationally, formal links between academia and the community have been evolving since at least the 1970 s, with the emergence of participatory research in Latin America and elsewhere (Office of Community-Based Research, 2009). A Canadian network was formed in 2008, known as CommunityBased Research Canada. Historically, two traditions have been discussed: the Northern and Southern Tradition. The Northern Tradition stems from social science and action research of Kurt Lewin, while the participatory action research or Southern Tradition stems from liberation pedagogy and such scholars as Paulo Freire and his work with oppressed communities (Pontes Ferreira \& Gendron, 2011; Minkler, 2005).

Currently within Canada, universities and granting agencies are placing increased prominence on such partnerships emphasizing community service, responding to community needs, and CBR (Office of Community-Based Research, 2009). Specific funding opportunities have also been implemented by federal granting agencies over the past decade, such as CURA, the Community University Research Alliance 
program, formed by the Social Sciences and Humanities Research Council of Canada (SSHRC) in 1999 (Office of Community-Based Research, 2009) and community-based research grants with the Canadian Institutes of Health Research (CIHR; e.g., HIV/AIDS Community-Based Research Grant). Consistent with these movements, $\mathrm{CBR}$ is on the rise (Flicker, Savan, Kolenda, \& Mildenberger, 2008).

Despite the general growth of CBR, access to relevant coursework and applied experiences in $\mathrm{CBR}$ or CP as a psychology trainee in Canada is limited, typically comprised of one or two course offerings total (if any) at most institutions, unless one completes training through one of the now only two freestanding CP university programs in Canada. These include one French language program in Quebec, at Université du Québec à Montréal (UQAM), and one English language program in Ontario, at Wilfrid Laurier University (as noted in Aubry et al., 2010, previously there was a second French language program at Universite Laval but it is no longer accepting students). Such opportunities are often even further limited as a trainee enrolled in a professional psychology program - that is, programs intended to train students in clinical, counselling, school and neuropsychology for registration as a practising psychologist. In our own experiences, only one of us (JB) completed any formal psychology graduate coursework in CP. A challenge we both faced (although for MT especially) was minimal psychology peer examples of CP or CBR, as well as difficulty locating and identifying with $\mathrm{CBR}$ examples in the literature - as this area of work is often conducted by non-psychologists and published in non-psychology journals (e.g., public health, sociology, etc.). The minimal exposure to such a significant research approach within our profession surely hinders the advancement of applied research in real-world settings by psychologists, as well as serves to limit their contributions to addressing social problems.

\section{Objectives}

Consequently, the aims of this paper are to: 1) highlight the implications of CBR for the broader professional psychology training community, notably ways in which professional psychology training can in fact be strengthened by incorporating training in $\mathrm{CP}$, and 2) relate these strengths and implications to key observations gleaned from conducting our own CBR projects as professional psychology graduate students. Our intention in providing examples of our personal experiences is to help bring these messages into a more psychology-relevant framework, as most existing CBR-related work has been discussed outside of psychology. We also recognize the disconnect between much of professional psychology and $\mathrm{CP}$, and thus we purposefully hope to target this paper at the professional psychology audience, for whom this information may be more novel. We appreciate that many of our observations will be familiar to individuals well-versed in CBR and CP thus, our goal is to be critically reflective rather than to present novel research for the field of CBR, and more importantly, to share these experiences in the context of professional psychology training. As such, we intend to speak both to those researchers who are not as familiar with CBR or CP (who perhaps are facing some of the same challenges we were as newcomers to the field), and to those psychologists involved in professional psychology training.

\section{Project Backgrounds}

Both of us actively sought out CBR projects primarily due to a desire to generate socially meaningful applied research. The first CBR project (MT) involved two geographically remote Aboriginal communities in northern Manitoba. A collaborative approach emerged as a result of an identified need to address Aboriginal youth suicide in each of these communities. The partnership was developed over a couple of years between MT and representatives of each community's health centres and band councils. Additionally, the partnership was facilitated by previous contacts between community representatives and $\mathrm{MT}$, within the context of a federally funded mental health services program for Aboriginal people in Manitoba. Over time, the project focus shifted from Aboriginal youth suicide to Aboriginal youth well-being. The resulting study was two surveys assessing well-being, providing evidence for the pivotal role of community-level supports in Aboriginal youth well-being (see Tiessen, Taylor, \& Kirmayer, 2009).

The second CBR project (JB) involved a culturally diverse lower-income and resource-poor urban community in Ottawa. A collaborative partnership arose in response to an identified need for greater accessibility (i.e., availability, relevancy, affordability) to physical activity for young people within this community. The partnership was developed over a couple of years between the University of Ottawa and three non-profit community organizations: a community health centre, a hip-hop organization, and the City of Ottawa. As a partnership, a needs assessment was conducted and in response to the findings, a new hip-hop dance program for young people aged 11 to 16 years was implemented and evaluated (see Beaulac, Bouchard, \& Kristjansson, 2009; Beaulac, Olavarria, \& 
Kristjansson, 2010). Despite the seemingly disparate contexts of these two CBR projects, the process of developing the partnerships and conducting the research was very similar, as were the contributions to our development as professional psychologists.

\section{Implications of CBR for Professional Psychology Training}

As a psychologist or trainee interested in CBR, there can be numerous barriers to pursuing such research. Common barriers and facilitators to doing CBR have been well articulated elsewhere, and consequently this literature will not be repeated in detail here. Interested readers are directed to these key sources in the literature for a further review. To summarize briefly, frequent challenges of CBR include: partnership, methodological, and broader sociocultural issues; time and resources, such as insufficient funding and institutional support for CBR; history of negative impacts from research and a corresponding legacy of mistrust of researchers. On the other hand, as noted above, CBR is a particularly valuable approach as it is associated with: more relevant research findings; improved recruitment and retention; increased quality and therefore internal and external validity of the research; better ability to capture the complexity of inequalities, and therefore, more likely to reduce inequalities; greater potential for increased community capacity; and, increased translation to action (see Benoit, Jansson, Millar, \& Phillips, 2005; Cardona, \& Joshi, 2007; Fleischman, 2007; Flicker \& Savan, 2006; Israel et al., 1998; Minkler, 2005; Suarez-Balcazar, Harper, \& Lewis, 2005; Viswanathan et al., 2004).

A strong argument can be made that psychological researchers would benefit from training in $\mathrm{CBR}$ - and would make valuable contributions to the $\mathrm{CP}$ literature. Yet, as noted, many graduates and trainees within the wider Canadian psychology community have limited or no exposure to CP or to CBR (Aubry, Sylvestre, \& Ecker, 2010). One potential reason is that such training would likely require most training programs to make some perceived key adjustments, as the principles and practice of CBR can be quite different from those encountered by researchers engaged in academically-driven research. As well, psychology as a discipline has historically focused on individual-level factors, and the identification of pathology (versus strengths). CP, on the other hand, has more of a positive psychology orientation, which presents an additional paradigm shift for many psychology departments. Furthermore, psychology in general faces particular barriers as it has historically been (and arguably continues to be) concerned with being regarded as a 'basic science'.
There are important differences between CBR and traditional scientific research in terms of ontology, epistemology, ideology, and methodology.

Traditional scientific research, which is typically associated with a positivist paradigm, assumes that there is one external reality that can be at least partially revealed by rigorously controlling for extraneous variables, emphasizes objectivity, and assumes that research can be value-neutral. Also, traditional scientific research is directed exclusively by researchers. Although CBR may be conducted from a number of paradigms, it has been suggested that critical theory and constructivism are most well suited to CBR. A critical theory paradigm assumes that there is an external reality but that it has evolved over time due to the influence of social-ecological factors, that interdependence exists between the researcher and participants and moreover, that the research process requires a dialogue between the researcher and participants, and that research is not value-neutral. A constructivist paradigm argues that reality is socially constructed and thus, multiple realities exist and can only be interpreted in the context of the relationship between researcher and participant (Israel et al., 1998).

Some key values that are reflected in both the critical theory and constructivist paradigms include participation and collaboration, respect for diversity, empowerment, consideration of context, social justice, and action; these are consistent with the overarching values of community psychology (Kloos et al., 2012). Whereas traditional scientific research tends to use primarily quantitative methods in controlled laboratory settings, CBR research tends to use a variety of methods. In the case of CBR research coming from a constructivist paradigm, the methods would be primarily qualitative (e.g., interview, ethnography), while from a critical theory paradigm they might be quantitative, qualitative, or mixed (Nelson \& Prilleltensky, 2005).

Regardless of the particular paradigm adopted, training in CBR would be a valuable complement for Canadian psychology, and particularly so for professional psychology. Some view scientific rigor or quality of research evidence as a key concern of CBR (Roche, 2008), whereas others would argue that CBR enhances the scientific quality and facilitates a deeper understanding (Horowitz, Robinson, \& Seifer, 2009; Minkler, 2005). In either case, psychological research could benefit from the contribution of CBR in the manner in which it facilitates translation to a real world context, thereby facilitating greater impact. With increasing importance being placed on translating evidence to practice and increasing the accessibility of research findings, it would appear 
that psychology could gain by integrating the practice of CBR into the discipline as a research approach. Professional psychology in particular has a responsibility to reduce the gap between research and practice in order to maximize impact on society

(Grimshaw et al., 2012).

CBR has in fact been identified as a recommended area of competency for health professionals by the Institute of Medicine (Gebbie, Rosenstock, \& Hernandez, 2003). Taking this point into consideration with those cited above, it is clear that $\mathrm{CP}$ and $\mathrm{CBR}$ offer unique opportunities for professional psychology training programs. As defined in the national Mutual Recognition Agreement of the Regulatory Bodies for Professional Psychologists in Canada (2001), core practice competencies of psychologists include skills in consultation, program evaluation, and interpersonal relationships - all of which can be well developed through CBR experiences. Furthermore, as Israel and colleagues (1998) have noted, key competencies of community-based researchers include the ability to engage in self-reflection, to be sensitive to power differences, to demonstrate respect for diversity, as well as to apply technical research skills. This description clearly mirrors the competencies expected of professional psychologists. These same competencies outlined for CBR and within the mutual recognition agreement of psychology regulatory bodies are also critically important to success in rapidly increasing inter-professional practice settings. Consequently, training in CBR can be seen as another avenue for programs to integrate science and practice from the outset of training, increase diversity training opportunities, and ensure that students are being trained to meet the service needs of the public - which one could easily argue indeed necessitates training in community-based work such as CBR.

In order for more programs to begin to incorporate $\mathrm{CP}$ and CBR approaches into their training curriculum, there are of course resource and system issues that would need to be addressed. As Aubry, Sylvestre, and Ecker (2010) noted, there are few official CP training programs in Canada. Moreover, despite the expectations of the prevailing training standards, there are only a minority of clinical psychology programs in Canada that offer any courses and training in community consultation and program evaluation (Aubry et al., 2010). There are certainly mechanisms, however, to build greater CP and CBR capacity within psychology that would not require the creation of new standalone programs. For example, programs can offer credit for community service learning and/or community consultation practica, or for relevant coursework completed outside of the psychology program (e.g., qualitative research and program evaluation courses are commonly found within departments of education). Online course offerings may also broaden students' access to relevant coursework, which indeed provides a pivotal foundation on which to base any subsequent applied work in CBR. Preferably, however, programs might consider hiring new faculty with training in $\mathrm{CBR}$ and $\mathrm{CP}$, such that relevant courses can be taught in-house and students can be supervised within the discipline of psychology (Aubry, Sylvestre, \& Ecker, 2010).

Another important change required within psychology programs is that of increased recognition for students and faculty engaged in CBR, including course and teaching credits, and equitable standards for meeting tenure requirements considering the different context of CBR as compared to laboratorybased research. Again, there exists as well considerable overlap in the objectives of $\mathrm{CP}$ and $\mathrm{CBR}$ and inter-professional education and practice. As inter-professional curricula become increasingly mandated within health-related disciplines across the country, this change could also facilitate greater training opportunities in $\mathrm{CBR}$. Indeed, $\mathrm{CBR}$ is an opportunity for psychological researchers to step outside of our often isolated research worlds, and 'join forces' with other disciplines.

We are convinced that our own CBR experiences have enhanced our ability to conduct relevant and effective research endeavours, as well as to be more attuned clinicians. Firstly, such experience with CBR has caused us to be keenly attentive to directly addressing the needs of communities, through gathering "consumer" input rather than personal research interests driving the research agenda, which may or may not be relevant to a community's needs. Secondly, we regularly find ourselves engaged in ongoing consideration of and reflection on biases, which also leads to an enhanced appreciation of "local" versus "expert" knowledge. This in turn enhances our ability to be responsive to individuals' needs, and to experience increased objectivity, empathy, and respect for those with whom we work. Furthermore, we are acutely aware of the importance of keeping goals realistic, whether in a research or a clinical context. Finally, our CBR experiences very effectively drive home an awareness that research results will not be utilized without a relevant knowledge translation (KT)/dissemination plan and most critically, local project ownership. Thus, we make a concerted effort to plan for KT and wide project ownership from the outset of any research planning. 
We also recognize how our training opportunities in $\mathrm{CP}$ and CBR have directly facilitated attainment of our professional positions since graduation. For JB, her CP and CBR training was invaluable to her recent clinical-academic position as a psychologist and assistant professor working in primary care, during which time her primary role included program development, evaluation, and consultation, with limited direct client contact. Without training in CBR, she would have been unprepared for this consultant position, which seems to be the future role of many professional psychologists within the public sector in Canada. Similarly for MT, upon graduation she worked as well in a clinical-academic position, largely providing clinical consultation, training, and program development services to a large rural community mental health program, as well as liaising with multiple community-based mental health services partners.

Given these underlying similarities between how we have each been shaped professionally by our individual CBR training experiences, also gave rise to discussion and reflection on the key lessons we took away from this training. These conversations occurred after we each completed our CBR projects, when we were struck by the parallels in our experiences. To further elucidate the influence of our CBR experiences on our development as professional psychologists, we base the following description of our personal observations on a framework proposed by Israel and colleagues (1998), highlighting three key categories of challenges within $\mathrm{CBR}$, including: (1) methodological issues; (2) partnership-related issues; and, (3) broader social, political, economic, institutional, and cultural issues.

\section{Reflections on Community-Based Research Themes}

\section{1) Methodology: Set realistic and flexible expectations}

\section{Our experiences:}

The importance of maintaining realistic and flexible goals was highlighted in various ways for each of us over the course of our respective CBR projects. For example, JB initially sought to conduct a randomized controlled trial of the new youth program, having been taught in her academic department that this was the gold standard of intervention research.

Community partners were very supportive of attempting this goal, although at the same time voiced their scepticism at its feasibility. In the end, the community's wisdom prevailed and the project was revised to a more realistic pre-post nonexperimental research design.
Both of our dissertation projects also provided an illustration of the competing pressures when managing CBR initiatives, especially related to time and finances. For instance, for MT, stalls occurred due to province-wide political tensions, quite vocal prohibitions from other academics against the (perceived inappropriate) cross-cultural use of scales, and the delay of community visits because of both inclement weather and an airline bankruptcy (!). In contrast, for JB, notable timing and financial issues arose starting with pressure from the communitybased funder to initiate the project immediately upon receiving funding. Once convinced of the importance of community involvement, there was then pressure to implement the program during Ramadan, despite there being a significant portion of young people in the community who would then not have been able to participate. Eventually, strong negotiation skills on the part of a community partner, in addition to a history of positive experiences between the community partner and funder, facilitated a more reasonable start date.

\section{Reflections on setting realistic and flexible expectations:}

This first observation, regarding setting realistic and flexible expectations, likely seems quite obvious. However it is very easy as a new researcher or clinician, especially within CBR, to become afflicted by the desire to "solve all the world's problems". Yet very quickly, CBR projects effectively drive home the importance of being realistic and flexible. As many avid travellers are aware, a rule of thumb when packing for a long trip is "take half the amount of clothes you think you will need but twice the amount of money." A similar rule applies to research in general, and especially to CBR: to maximize the likelihood of a successful project, cut the goals in half but double the money and time required. Moreover, given the significant differences between obtaining an academic degree/maintaining an academic position and meeting the needs of a community, CBR requires flexibility in order to balance competing demands. Specifically, the demands of academia such as conducting rigorous and controlled research and publishing in peer reviewed journals may at times compete with community needs for transparency and active participation. Even the process of acquiring ethics approval for a project can compete with the reality of CBR projects which may be conceptualized over a longer period of time with the input of multiple participants. For both of us, the key to arriving at mutually realistic goals was to engage in ongoing dialogue. Indeed, a goal is more likely to be realistic if both the community and academic partners are 
comfortable with the plan.

We particularly encourage any interested newcomers to CBR within academia to set realistic expectations, as completion of degree requirements or advancement within academia depend on completing projects within a timely manner and on the production of knowledge dissemination within scholarly venues. It can be a challenge to balance the requirements of a CBR project that include lengthier start-up times to build relationships and negotiate the objectives and parameters of the project with the time-structured requirements of granting agencies and universities. Additionally, for students in professional psychology programs, who are tasked with balancing the demands of research, coursework, and practical experiences, setting realistic expectations is of critical importance. This is true both for one's research as well as when working with clients in therapy.

From our perspective, one way to enhance the success of meeting these competing challenges, particularly as a student attempting to complete a thesis or dissertation or as an early career psychologist, is to become involved with an ongoing CBR project instead of developing a project from scratch, and/or to plan for a smaller project than would be expected of non-CBR research (e.g., smaller sample size, fewer studies). A smaller or ongoing project may lack freedom to research any topic or to acquire extensive skills in project management, yet more importantly it can offer an already established context and is likelier to have more realistic timelines, as well as greater financial and human resources and established relationships a key aspect of CBR we turn to next.

2) Partnership: Clearly define each partner's role and develop and maintain positive relationships and open lines of communication

Our experiences:

For MT, positive relationships with some of the community members were already established before the actual research project began, which were instrumental in initiating and maintaining the project. However, there are aspects to building respectful, trusting relationships which are common across research endeavours, regardless of one's prior contacts. For both of us, the development of relationships was accomplished over a number of months through letters, faxes, telephone calls, and inperson, in-community meetings and discussions with key community partners and various other community members. These contacts served to develop the research partnership as well as to define roles and priorities.

When building relationships, we both recognized that there was no substitute for the value of informal encounters and activities. For each of us this occurred in the form of conversations with fellow travel passengers, hanging out at community centres, getting to know participants over a community meal, and just being seen in the context of the community.

Both of us invested significant time in learning about important community and youth issues, developing relationships with community members, and generally becoming a recognizable face. A similar iterative process was employed in developing the research instruments, in order to respect and benefit from the principles of community involvement and application of local knowledge. Such steps are not normally necessary in university-based research, but proved to be crucial for each of our CBR projects. There value of simply "hanging out" was underscored for both of us when youth expressed excitement regarding our repeated presence in the community - for example, incredulously exclaiming to MT on an early community visit "You're back?!"

Reflections on clear roles, positive relationships, and open communication:

Role definition and relationship development were key observations from each of our CBR experiences. Indeed, the relationship between the researcher(s) and the community is the backbone of CBR, and a lack of clarity in roles is a commonly experienced challenge to doing CBR (Flicker \& Savan, 2006). We both admit that the importance of formally defining each research partner's role was primarily learned in hindsight by each of us. At the outset of our CBR projects, codes of research ethics specific to Aboriginal health or CBR more generally were still in development, and consequently the need for a formal "contract" was less clear for either of us. Informally, we each took similar measures as are outlined in these codes of ethics, to establish clear and transparent goals, and to build trust and respect. For example, the participating communities who were part of each CBR project gave their written consent and commitment to the research, and at the time, this informal method was acceptable. We both recognize now, however, that it is likely that a formal agreement outlining each party's expected contribution could have facilitated the research process. In particular, this would have been an opportunity to be more explicit about ways to increase capacity building and to better integrate what was learned from the research results into ongoing community work. At the same time, it is important to remember that while documents can lay 
the foundation for, and provide a useful record of the research relationship, they do not constitute the relationship. The ongoing, active negotiation of relationships between researchers and community partners is what matters most in the end. This issue must be given attention at all stages of the research process, not only at the beginning.

We also note that it was not always easy to find ways in which to fully address each CBR guideline. For example, pragmatic issues of financial resources limited MT's ability to directly contribute to capacity building in the communities. Such challenges highlight the reality that while new CBR ethical guidelines represent a significant improvement over the practices of the past (particularly with Aboriginal groups), they are still a work in progress. Knowing what community-based research guidelines are is very different from knowing how to enact them, and from being able to do so. This is true for both academic researchers and community members. While codes of research ethics can provide appropriate directions, both parties in the research partnership need to know how to follow these directions and in the best ways possible. Just as Western-trained academics are learning how to engage in improved community-based research, community members must also have appropriate opportunities to learn how to engage in meaningful and beneficial research partnerships. Such increased awareness can develop with time and experience, but can also be facilitated through various resources now available (for example, Access Alliance Multicultural Health and Community Services, 2011; The Examining Community-Institutional Partnerships for Prevention Research Group, 2006). Additionally, research guidelines must be considered within the appropriate historical, socio-political, and physical context, unique to each community, which is an important component of our final research theme.

\section{3) Broader Issues: Identify your personal biases and work to reduce power imbalances}

Our experiences:

Power comes in a variety of forms, such as simply by virtue of taking on the role of a researcher (versus participant), through university affiliation, or particularly through access to money. For JB's project, funding went through one of the community partners, which served to reduce the power imbalance (which typically favours academia) and also likely increased the sense of community ownership of the project.

For MT, the issue of biases was underscored through contact with a young man working in one of the communities as a missionary. While on one hand the missionary was sharing positive messages with community members about the power of spiritual beliefs in well-being, on the other hand these messages could be construed as an imposition of outside views, with an uncomfortable connection to past colonization efforts. This meeting was an unexpected occurrence for MT, which contributed to many layers of self-reflection.

\section{Reflections on recognizing biases and power imbalances:}

While the description above of our actual experiences is short, the theme of power and biases became a central lesson in both of our dissertation projects, and has been emphasized by other community-based researchers as well (e.g., Macaulay et al., 1999; Minkler, 2005; Suarez-Balcazar, Harper, \& Lewis, 2005). Continuously reflecting on the research process is a necessary ingredient for responsible and worthwhile CP, CBR, and, we would argue, for all psychological research. For example, some pivotal CBR questions include: Who decides what is best for the community? How can one ensure that the person/people deciding are acting out of knowledge of what in fact is best? The answers to these questions are seldom clear or straightforward, and will be different for each community, thus highlighting the ongoing importance of reflection, particularly given that biases can exist in many forms; some obtrusively clear, while others so subtle one may not even recognize them. For example, Western academia represents a specific way of thinking, which in some ways overlaps with, but in many ways is divergent from culturally-specific views of health and well-being, such as those of individuals from collectivist societies. Furthermore, a psychological understanding of well-being is different from a sociological, medical, and definitely a traditional Aboriginal understanding of wellness. Similarly, an academic viewpoint can be quite different from an applied view (e.g., university versus hospital-based research).

While differing viewpoints are not always incompatible, blindly accepting one as the sole explanation creates a very unbalanced situation. This is particularly true when one perspective is connected to a position of higher power or status (Taylor, 2002), as is the historical case when comparing Indigenous and Western worldviews, or minority and majority groups in general. Indeed, for many Aboriginal people, colonization has resulted in a loss of independence and power, as well as the suppression, and often the eradication, of traditional cultural ways. Certainly in some cases aspects of traditional cultural 
identity remain, but often in a broken form, leading to a situation of cultural identity confusion (Royal Commission on Aboriginal Peoples, 1996). In various ways, the assimilationist policies of the Canadian government (as well as the governments of other countries) have amounted to systematic efforts to undermine the autonomy of Aboriginal people.

The history of disregard for culture and autonomy experienced by these communities (as by many others) is mirrored by the history of Aboriginal health research in Canada. All too often in the past, outside researchers have played out the stereotype of "helicopter research": dropping into a community, collecting data, and then flying out, never to be seen or heard from again (Macaulay, Delormier, Cargo, McGregor, \& Norton, 2002). Outside researchers tended to use community research results to further their own careers, rather than to focus on the needs of, and potentially constructive outcomes for, the community. To some extent, this approach stemmed from the same government policies, which were responsible for the devastating historical effects of colonization for Aboriginal groups across the country. As a result, much previous research on Aboriginal populations, and likewise for many other historically disadvantaged groups, has not produced any benefit for communities, and instead has led in some cases to direct and indirect harm. For example, particularly with medically-based research, there have been reports of researchers using community members' blood or tissue samples for purposes to which consent was never given and confidentiality was not respected (Schnarch, 2004). Furthermore, many research projects have focused solely on problem areas, perpetuating and even creating negative images of minority communities. Taken together, these negative experiences have created a tendency in many communities to mistrust outside researchers and research projects in general. "We've been researched to death" is a common statement, which reflects the position of many Aboriginal groups vis-à-vis research.

Fortunately, the past decade has seen efforts to improve upon this historical legacy of colonization and negligent research. One starting point has been the recognition that much previous research has in fact been carried out not by university-based researchers but by government officials (Schnarch, 2004). There is a significant difference between government research, which has tended to be more on the side of data collection for surveillance purposes, and genuine applied research, especially research which reflects the priorities of Aboriginal communities. Furthermore, while certain communities may feel over-researched, many have under-benefited from previous research efforts. There are many gaps within the area of Aboriginal health research, particularly in regards to research which speaks to community priorities. One of these key priorities is in the area of mental health, an area which has been much less researched, and to which psychology can make many valuable contributions. Additionally, there is a pressing need in the current political climate for research that can provide concrete, objective information to support policy and program decisions. In other words, data is needed in order to access money and resources, which can be used to address important community issues.

Ultimately, CBR, and good research in general, require continued self-reflection from various perspectives - interpersonal, academic, cultural, religious, and historical. Being aware of one's own biases also encourages the maintenance of an open, tolerant mindset. For valuable research to be produced, it is crucial to stay open to both new ideas and new experiences.

\section{Conclusion}

"Doing respectful research in ... communities takes more time, more money, and arguably, moral fibre." (Schnarch, 2004, p.84)

Conducting a CBR project, particularly as a student or newcomer to the area, can be a challenging yet exceptionally rewarding experience. In addition to the usual academic lessons obtained while completing a professional degree and/or conducting a longer-term program of research, CBR projects offer the opportunity to gain valuable experience working collaboratively in an applied context, which ideally can contribute to positive changes in individual's lives - an aspiration that all professional psychologists share. Furthermore, CBR methods are ideal for obtaining direct consumer input on important public health matters, such as improved access to mental health services and enhanced chronic disease management, priorities highlighted by the Mental Health Commission of Canada (www.mentalhealthcommission.ca).

Depending on the research question and context, CBR may not be the most suitable approach but it is an important approach that clearly provides many benefits to both researchers and communities, and thus ought to be taught and supported within the field of psychology more generally. There is much to be gained from approaching a program of research through a focus on a combination of: (a) relationships developed with community members, (b) an appreciation for the relevant historical and political issues, and (c) decisions based on respect for both 


\section{Global Journal of Community Psychology Practice}

ethical guidelines and community needs. We strongly encourage students and training programs to make $\mathrm{CP}$, and CBR specifically, a component of their professional psychology training. Such steps can assist in carving out a more prominent place for community psychology within psychology as a whole, as well as contribute to professional psychology playing a more influential role in addressing the many contemporary social problems.

\section{References}

Access Alliance Multicultural Health and Community Services (2011). Community-Based Research Toolkit: Resource for Doing Research with Community for Social Change. Toronto: Access Alliance Multicultural Health and Community Services. Available from: http://accessalliance.ca/sites/accessalliance/files/ CBR Toolkit Jan2012.pdf

Aubry, T., Sylvestre, J., \& Ecker, J. (2010). Community psychology training in Canada in the new millennium. Canadian Psychology, 51, 8995. doi:10.1037/a0018134

Beaulac, J., Bouchard, D., \& Kristjansson, E. (2009). Physical activity for adolescents living in an underprivileged neighbourhood: Views of parents and adolescents on needs, barriers, facilitators, and programming. Leisure, 33, 537561. doi:10.1080/14927713.2009.9651452

Beaulac, J., Olavarria, M., \& Kristjansson, E. (2010). A community-based hip-hop dance program for youth in a disadvantaged community in Ottawa: Implementation Findings. Health Promotion Practice, 11 (Supp 1), 61S-69S. doi:10.1177/1524839909353738

Benoit, C., Jansson, M., Millar, A., \& Phillips, R. (2005). Community-academic research on hardto-reach populations: Benefits and challenges. Qualitative Health Research, 15, 263-282. doi:10.1177/1049732304267752

Cardona, M., \& Joshi, R. (2007). The challenge of balancing methodological research rigour and practical needs in low-income settings: What we are doing and what we need to do better. Critical Public Health, 17, 81-89. doi:10.1080/09581590601045238

Fleischman, A.R. (2007). Community engagement in urban health research. Journal of Urban Health, 84, 469-471. doi:10.1007/s11524-007-9166-6

Flicker, S., \& Savan, B. (2006). A snapshot of CBR in Canada. Toronto, ON: Wellesley Institute. Retrieved from:
http://depts.washington.edu/ccph/pdf_files/CBR $\% 20$ snapshot $\% 20$ report $\% 20$ final.pdf

Flicker, S., Savan, B., Kolenda, B., \& Mildenberger, M. (2008). A snapshot of community-based research in Canada: Who? What? Why? How? Health Education Research, 23, 106-114. doi:10.1093/her/cym007

Gebbie, K., Rosenstock, L., Hernandez, L.M. (2003). The Future of the Public's Health in the $21^{\text {st }}$ Century. Washington, DC: National Academies Press, Institute of Medicine.

Grimshaw, J.M., Eccles, M.P., Lavis, J.N., Hill, S.J., and Squires, J.E. (2012). Knowledge translation of research findings. Implementation Science, 7, 50 .

Horowitz, C. R., Robinson, M., \& Seifer, S. (2009). Community-Based Participatory Research From the Margin to the Mainstream. Are Researchers Prepared? Circulation, 119, 2633-2642.

Israel, B.A., Schulz, A. J., Parker, E.A., \& Becker, A.B. (1998). Review of community-based research: Assessing partnership approaches to improve public health. Annual Review of Public Health, 19, 173-202.

Kloos, B., Hill, J., Dalton, J. H., Elias, M., Wandersman, \& Thomas, E. (2012). Community Psychology: Linking Individuals and Communities. Belmont, CA: Wadworth.

Macaulay, A.C., Commanda, L.E., Freeman, W.L., Gibson, N., McCabe, M.L., Robbins, C.M., \& Twohig, P. (1999). Participatory research maximises community and lay involvement. British Medical Journal, 319, 774-778.

Macaulay, A. C., Delormier, T., Cargo, M., McGregor, A., \& Norton, L. (2002). Introduction to the theory and practice of participatory research. Unpublished Workshop Ethics and Practice of Participatory Community Research.

Minkler, M. (2005). Community-based research partnerships: Challenges and opportunities. Journal of Urban Health, 82 (Supp 2), ii3-ii12. doi:10.1093/jurban/jti034

Mutual Recognition Agreement of the Regulatory Bodies for Professional Psychologists in Canada. (2001). Retrieved from http:/www.cpa.ca/docs/file/MRA2004.pdf

Nelson, G. \& Aubry, T. (2010). Introduction to community psychology in Canada: Past, present, and future. Canadian Psychology, 51, 77-78. 
doi:10.1037/a0019740

Nelson, G. \& Lavoie, F. (2010). Contributions of Canadian community psychology. Canadian Psychology, 51, 79-88. doi:10.1037/a0017570

Nelson, G. \& Prilleltensky, I. (2005). Values for community psychology. In G. Nelson \& I. Prilleltensky (Eds.), Community psychology. In pursuit of liberation and well-being (pp. 47-69). New York: Palgrave MacMillan.

Office of Community-Based Research (2009). The funding and development of community university research partnerships in Canada. Evidence-based investment in knowledge, engaged scholarship, innovation and action for Canada's future. Office of Community-Based Research, University of Victoria. Retrieved from http://communityresearchcanada.ca/documents/C BRFunding052009.pdf

Pontes Ferreira, M. \& Gendron F. (2011). Community-based participatory research with traditional and indigenous communities of the Americas: Historical context and future directions. International Journal of Critical Pedagogy, 3 (3), 153-168.

Roche, B. (2008). New directions in communitybased research. Wellesley Institute. Retrieved from http://wellesleyinstitute.com/files/newdirectionsi ncbr.pdf

Royal Commission on Aboriginal Peoples. (1996). People to People, Nation to Nation: Highlights from the Report of the Royal Commission on Aboriginal Peoples. Ottawa: RCAP.

Schnarch, B. (2004). Ownership, control, access, and possession (OCAP) or self-determination applied to research: A critical analysis of contemporary First Nations research and some options for First Nations communities. Journal of Aboriginal Health, 1, 80-95. Retrieved from: http://www.naho.ca/jah/english/jah01_01/journal _p80-95.pdf
Suarez-Balcazar, Y., Harper, G.W., \& Lewis, R. (2005). An interactive and contextual model of community-university collaborations for research and action. Health Education \& Behavior, 32, 84-101. doi:10.1177/1090198104269512

Taylor, D.M. (2002). The Quest for Identity: From Ethnic Minorities to Generation Xers. New York: Praeger.

The Examining Community-Institutional Partnerships for Prevention Research Group. (2006). Developing and Sustaining Community-Based Participatory Research Partnerships: A SkillBuilding Curriculum. Available from: www.cbprcurriculum.info

Tiessen, M., Taylor, D.M., \& Kirmayer, L.J. (2009). A key individual-to-community link: The impact of perceived collective control on Aboriginal youth well-being. Pimatisiwin: A Journal of Aboriginal and Indigenous Community Health, 7, 241-267. Retrieved from:

http://www.pimatisiwin.com/online/wpcontent/uploads/2010/jan/05TiessenTaylorKirma yer.pdf

Viswanathan, V., Ammerman, A., Eng, E., Gartlehner, G., Lohr, K.N., Griffith, D., ...Whitener, L. (2004). Community-based participatory research: Assessing the evidence. (Summary, Evidence Report/Technology Assessment No. 99; AHRQ Publication No. 04E022-1). Rockville, MD: Agency for Healthcare Policy and Research. Retrieved from: http://www.mycbpr.org/CBPRproject/articles/AHRQ-cbpr-assessingevidence.pdf

Wallerstein N, Duran B (2003). The theoretical, historical, and practice roots of community based participatory research and related participatory traditions. (Chapter 2, p. 25-46): In Minkler M, Wallerstein N, Eds), Community Based Participatory Research for Health. San Francisco, CA: Jossey-Bass. 